Research Paper: Gerotarget (Focus on Aging)

\title{
Involvement of NF-KBIZ and related cytokines in age-associated renal fibrosis
}

\author{
Ki Wung Chung ${ }^{1}$, Hyeong Oh Jeong ${ }^{1}$, Bonggi Lee ${ }^{1}$, Daeui Park ${ }^{1,2}$, Dae Hyun Kim ${ }^{1}$, \\ Yeun Ja Choi ${ }^{1}$, Eun Kyeong Lee ${ }^{1}$, Kyung Mok Kim ${ }^{1}$, June Whoun Park ${ }^{1}$, Byung Pal \\ Yu ${ }^{3}$ and Hae Young Chung ${ }^{1}$ \\ ${ }^{1}$ Department of Pharmacy, College of Pharmacy, Pusan National University, Busan, 46241, Republic of Korea \\ 2. Systems Toxicology Research Center, Korea Institute of Toxicology, Daejeon, 34114, Republic of Korea \\ ${ }^{3}$ Department of Physiology, The University of Texas Health Science Center at San Antonio, San Antonio, TX, 78229, USA \\ Correspondence to: Hae Young Chung, email: hyjung@pusan.ac.kr
}

Keywords: NF-KBIZ, aging, inflammation, renal fibrosis

Received: July 13,2016 Accepted: January 04, $2017 \quad$ Published: January 12, 2017

\section{ABSTRACT}

Chronic inflammation is a major contributor to age-related nephropathic changes, including renal fibrosis. In this study, various experimental paradigms were designed to delineate the role played by NF-KBIZ (also known as IKBל) in age-associated renal fibrosis. Analyses based on RNA-sequencing findings obtained by next generation sequencing (NGS) revealed the upregulations of NF-KBIZ and of IL-6 and MCP-1 (both known to be regulated by NF-KBIZ) during aging. The up-regulation of NF-KBIZ in aged rat kidneys coincided with increased macrophage infiltration. In LPS-treated macrophages, oxidative stress was found to play a pivotal role in NF-KBIZ expression, suggesting age-related oxidative stress is associated with NF-kBIZ activation. Furthermore, these in vitro findings were confirmed in LPS-treated old rats, which showed higher levels of oxidative stress and NF-KBIZ in kidneys than LPS-treated young rats. Additional in vitro experiments using macrophages and kidney fibroblasts demonstrated NF-KBIZ and related cytokines participate in fibrosis. In particular, increased levels of NF-KBIZ-associated cytokines in macrophages significantly up-regulated TGF- $\beta$ induced kidney fibroblast activation. Moreover, experiments with NF-KBIZ knocked down macrophages showed reduced TGF- $\beta$-induced kidney fibroblast activation. The findings of the present study provide evidence regarding an involvement of NF-KBIZ in age-associated progressive renal fibrosis and provides potential targets for its prevention.

\section{INTRODUCTION}

Chronic inflammation is a major risk factor that underlies various chronic diseases [1]. Although the inflammatory process is a normal, acute, defensive response to infection or tissue damage, unresolved lowgrade chronic inflammation exacerbates age-related diseases and the effects of aging at the molecular level via the NF-kB (nuclear factor kappa-light-chain-enhancer of activated B cells) pathway, as delineated by the molecular inflammation hypothesis [2]. This hypothesis provides insight of the oxidative stress-induced molecular pathway and links age-related physiological changes and the pathogenesis of many age-related diseases.
Age-related inflammation has several characteristic features, such as, dysregulation of the immune systems and increased oxidative stress, and dysregulation of the immune system is primary cause of inflammation during aging $[3,4]$. Dysregulation of the innate immune system is characterized by persistent inflammatory responses involving multiple immune and non-immune cells. Redox imbalance during aging also insidiously increases inflammation due to the continuous production of reactive oxygen species (ROS). Evidence strongly suggests that chronic up-regulation of NF- $\mathrm{kB}$ induced by immune system dysregulation and aberrant oxidative stresses provokes the expression of pro-inflammatory mediators, like TNF- $\alpha$, IL- $1 \beta$, IL-6, COX-2, and iNOS, during the 
aging process.

$\mathrm{NF}-\kappa \mathrm{B}$ inhibitor zeta (NF-kBIZ, also known as MAIL and $\mathrm{I} \kappa \mathrm{B} \zeta$ ), which is encoded by $N F K B I Z$, is an atypical nuclear member of the I $\kappa \mathrm{B}$ family [5]. NF$\kappa B I Z$ has been recently implicated in differential NF$\kappa \mathrm{B}$ target gene expression in immune cells, although its physiological function remain largely unknown [6]. Unlike other classical I $\kappa \mathrm{B}$ proteins that are constitutively expressed and controlled by degradation, NF- $\mathrm{KBIZ}$ expression is barely detectable in unstimulated cells, but when cells are stimulated with various inflammatory stimuli, it is rapidly induced [5]. NF-кBIZ has been suggested to regulate $\mathrm{NF}-\mathrm{\kappa B}$ signaling, as reporter analyses indicated NF- $\mathrm{\kappa BIZ}$ may act as an inhibitor of NF$\kappa \mathrm{B}$ [7]. In contrast, other studies have demonstrated that $\mathrm{NF}-\kappa \mathrm{BIZ}$ can induce the gene expressions of individual genes targeted by NF-kB, such as, IL- 6 and MCP-1 in macrophages $[8,9]$. However, its role in aged nephropathic conditions has not been explored to date.

Progressive renal fibrosis is the final pathway common to all renal diseases that ultimately lead to end-stage renal failure $[10,11]$, a devastating condition requiring dialysis or kidney transplantation [12]. The presence of progressive renal fibrosis manifests as reduced excretory function (reduced glomerular filtration rate) and elevated urinary protein excretion [13]. It has been well established that renal aging is associated with structural changes in kidneys, such as, glomerulosclerosis, interstitial fibrosis, and tubular atrophy $[14,15]$. Aging disturbs normal renal structure-function relationships for many reasons, which include the dysregulation of cellular energy sensors, oxidative stress, mitochondrial dysfunction, and abnormal immune functions that compromise nephron structural integrity with progressive renal fibrosis [16]. Recently, renal aging was highlighted in an investigation of renal structural changes in healthy kidney donors [17]. The authors observed subclinical age-related nephropathy on implantation renal biopsy of donors, which was undetectable by conventional clinical diagnostic testing. The investigators concluded that age-related structural changes in the kidney occur earlier than they previously expected [17]. Of the many fibrosis-driving signals, inflammation is a common feature of many fibrosis-related diseases [18].

Although the roles of NF-kBIZ have been investigated in many immune cells, its physiological roles have not been as extensively addressed. In the present study, we sought to delineate the role played by NF- $\mathrm{kBIZ}$ in age-associated renal fibrosis using systems biological and biochemical approaches. In addition, because aberrant oxidative stresses are known to be associated with the aging process, we investigated the role of oxidative stress on NF- $\mathrm{kBIZ}$ activation. Based on our systems biology results and biologic experimental results, we examined the role played by NF-kBIZ in age-related progressive renal fibrosis.

\section{RESULTS}

\section{The importance of the NF-kBIZ gene by RNA sequencing analysis}

The statistical significance of genes related to the NF- $\kappa \mathrm{B}$ family was tested by RNA-Seq analysis of NGS data as determined in previous studies [19] and Materials and Methods (Supplementary Table 1). Of the NF-кB

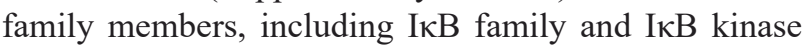
(IKK) complex, NF-kBIZ was the only gene found to be significantly up-regulated in aged rats kidneys (3.305 fold up-regulated; Q value $=0.00577$; Supplementary Table 1) .

Because NF-kBIZ was recently implicated in differential NF- $\kappa B$ target gene expression in immune cells, we analyzed 360 target genes of NF-kB in the Dr. Thomas Gilmore database (http://www.bu.edu/nf-kb/ gene-resources/target-genes). We found 54 of these genes were differentially expressed in young and old male Sprague Dawley (SD) rat kidneys (Q value $<0.05$, Supplementary Table 2). Furthermore, of these 54 genes, 51 were up-regulated in aged kidneys, suggesting the importance of NF- $\mathrm{kB}$ and of inflammation in the aging process (Supplementary Table 3, Supplementary Figure 1). Surprisingly, IL-6 and MCP-1, which are known to be regulated by NF-kBIZ, were also significantly up-regulated in old rats as compared with young rats (6.761 fold up-regulated, $Q$ value $=0.008,3.599$ fold upregulated, $\mathrm{Q}$ value $=0.001$ respectively, Supplementary Table 3). In addition, IL-6 receptor was also significantly up-regulated by aging by 2.908 fold ( $\mathrm{Q}$ value $=0.013$, Supplementary Table 3). These observations indicate NF$\kappa B I Z$ and its related genes were significantly up-regulated.

\section{Validation of RNA-sequencing data by biochemical analysis}

To confirm age-related NF-кB target genes expression using RNA-Seq data, quantitative PCR was performed. The genes were selected based on associations with NF-kBIZ or with other well-known target genes of $\mathrm{NF}-\kappa \mathrm{B}$. As shown in Figure 1, NF- $\mathrm{KBIZ}$ and its related genes (IL-6, MCP-1, and IL-6R) were all significantly up-regulated during renal aging. TNF $\alpha$ and IL- $1 \beta$ were also up-regulated, but to a lesser extent than NF-кBIZ related genes (Figure 1A). These results indicate the importance of NF-kBIZ and its related proteins, and confirm RNA-Seq data from NGS. To further confirm the role of increased NF- $\kappa$ BIZ in aged kidneys, the protein expression of NF-אBIZ and its related cytokine changes were examined in young and old rat kidneys. In agreement with previous results [20], nuclear p65 and p50 protein levels increased with aging (Figure 1B). In addition, the expression of NF-KBIZ protein was elevated in the 
nuclear fractions of aged kidneys, which concurred with qPCR data (Figure 1B). Furthermore, the protein levels of NF- $\kappa$ BIZ related cytokines were also up-regulated in aged kidney (Figure 1B, 1C). Serum IL-6 levels were also increased in aged rat (Figure 1D). To further assess the effects of increased levels of NF- $\mathrm{KBIZ}$-related cytokines, the activation of IL-6 signaling was investigated in young and old rat kidneys. The activation of IL- 6 by its receptor leads to the phosphorylation of JAK2 and the nuclear translocation of STAT3. Aged kidneys showed increased JAK2 phosphorylation and significantly higher levels of STAT3 and of phosphorylated STAT3 in nuclear fractions (Figure 1E). These findings confirm that the up-regulations of NF- $\kappa$ BIZ and of its related cytokines induces IL- 6 , and thus, upregulates the JAK2/STAT3 signaling pathway in the kidneys of aged rats.

\section{NF-אBIZ in aged kidneys and macrophage infiltration}

To examine whether increased NF- $\kappa \mathrm{BIZ}$ is associated with the infiltration of immune cells during aging, we performed immunohistological analysis.

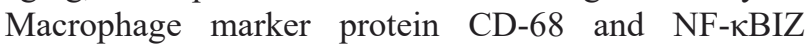
were found to colocalize in aged rat kidneys by immunofluorescence (Figure 2A). CD-68 positive area as well as colocalization between CD-68 and NF- $\mathrm{KBIZ}$ was increased in aged rat kidneys (Figure 2B, 2C). Immunohistochemistry showed increased macrophage infiltration in old rats (Figure 2D). These data suggest that increased NF- $\kappa \mathrm{BIZ}$ during aging is associated with increased infiltration of macrophages during aging.
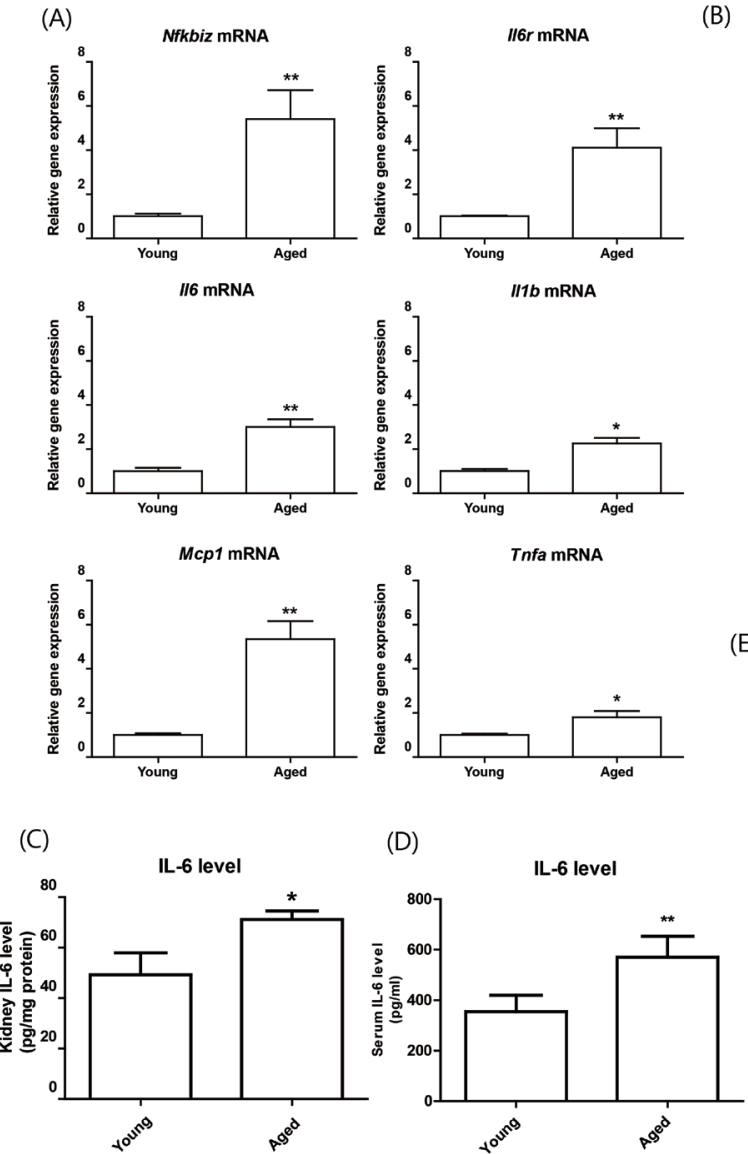

(B)
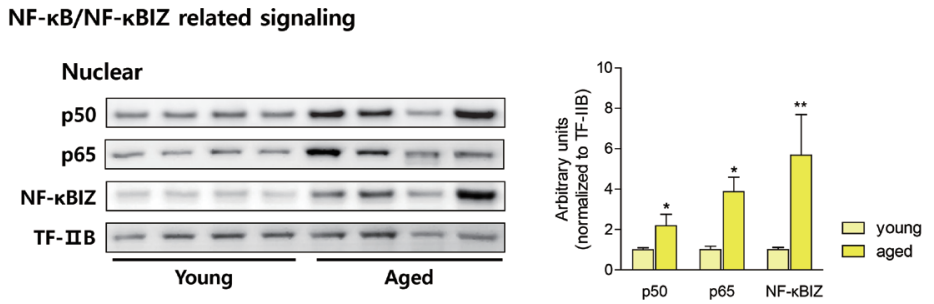

NF-kBIZ associated cytokine/chemokine
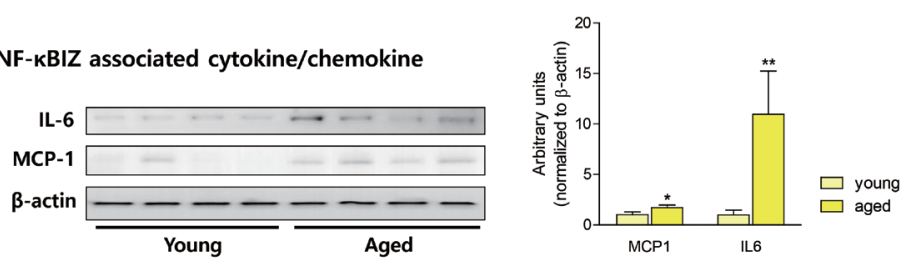

(E)

IL-6 related signaling
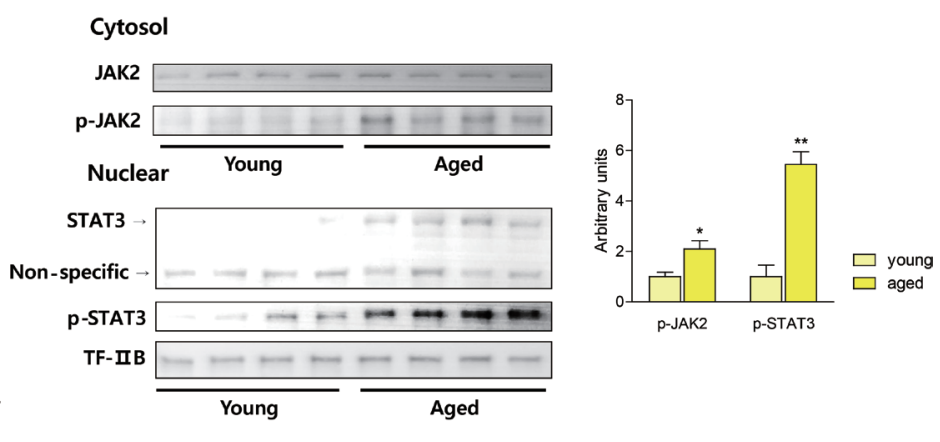

Figure 1: Increased NF-кBIZ and NF-кBIZ-related signaling in aged rat kidney. Young (6 month) and old (24 month) rat kidneys were used to validate NGS data. A. The mRNA expressions of Nfkbiz, Il6, Mcpl, Il6r, Tnfa, and Illb were measured by qPCR in young and old rat kidneys $(n=6)$. Results were normalized $v s$. Gapdh. Data are expressed as means \pm SEMs. $* P<0.05 v s$. the young group.

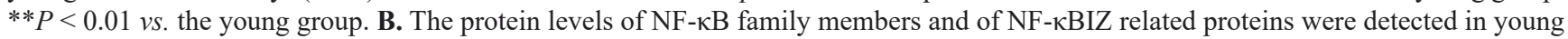
and old rat kidneys. Western blots were performed to estimate the nuclear protein levels of p50, p65, and NF- $\kappa$ BIZ in nuclear fractions of old kidneys. TF-IIB was used as a loading control. NF- $\kappa$ BIZ related cytokines (IL-6, MCP-1) were detected by Western blotting. $\beta$-Actin was used as the loading control. C. Kidney IL-6 levels were determined by ELISA. Data are expressed as means \pm SEMs. $* * P<0.01 v s$. the young group. D. Serum IL-6 levels were determined by ELISA. Data are expressed as means \pm SEMs. $* * P<0.01$ vs. the young group. E. IL-6 downstream signaling pathway (JAK-STAT pathway) were detected in young and old rat kidneys. Western blotting was used to assess the protein levels of JAK2 and phosphorylated-JAK2 in cytosolic fractions of aged kidneys, and Stat 3 and phosphorylated-Stat3 in nuclear fractions of aged kidneys. TF-IIB was used as the loading control. 
(A)
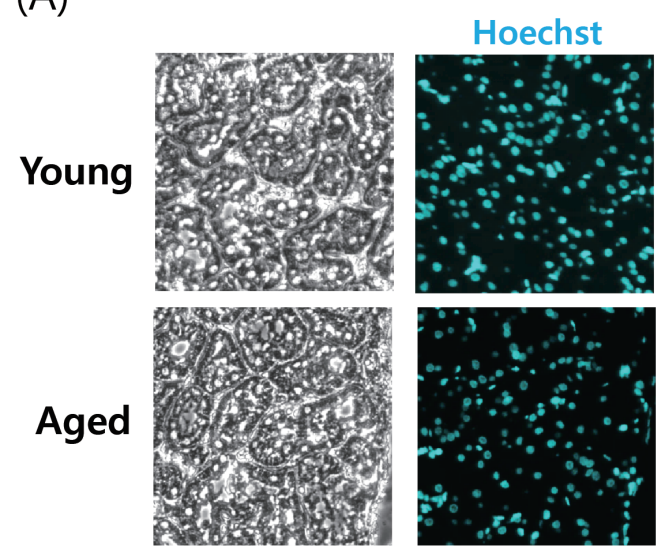

(B)

CD68 positive area
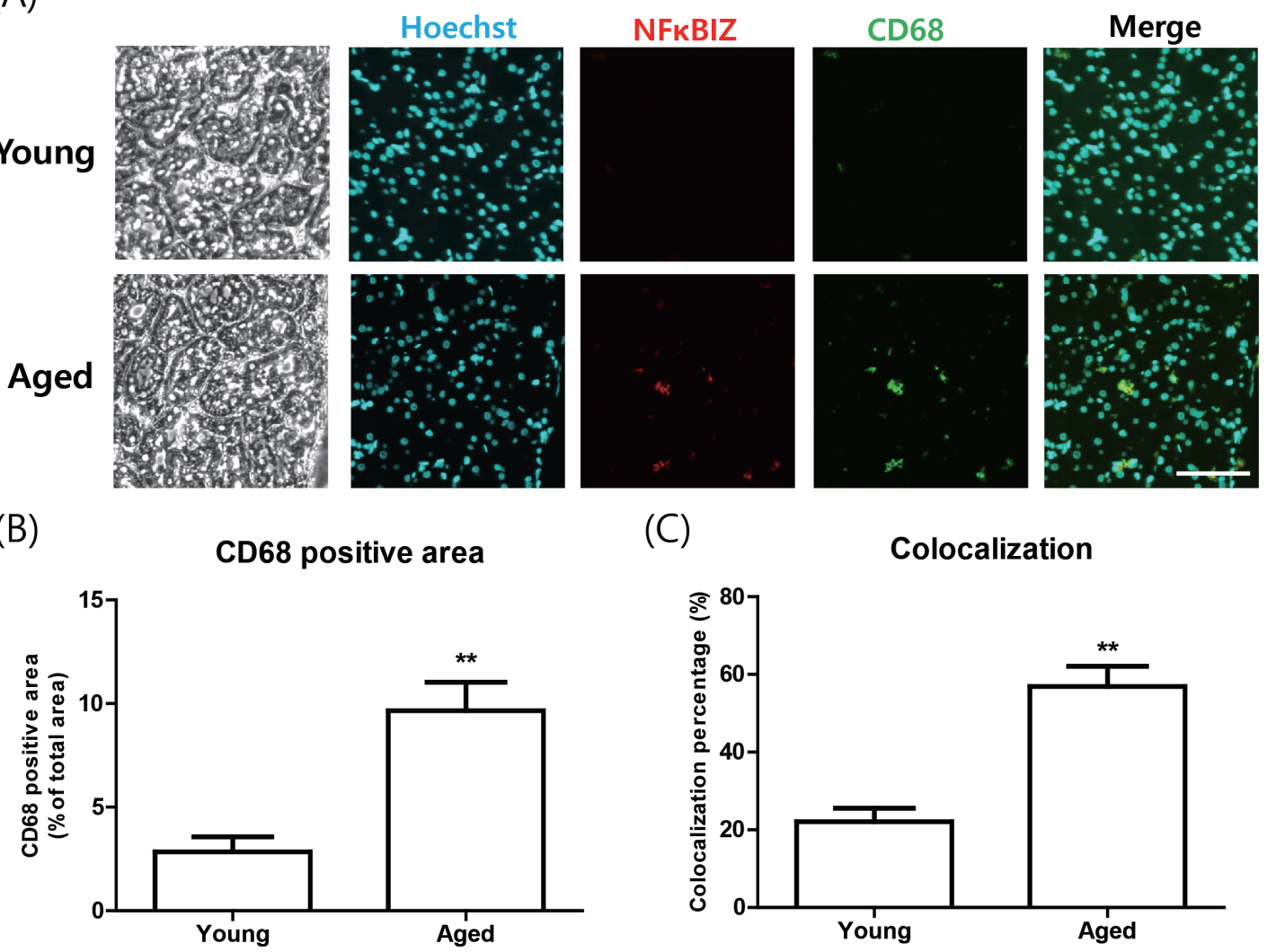

(C)

\section{Colocalization}

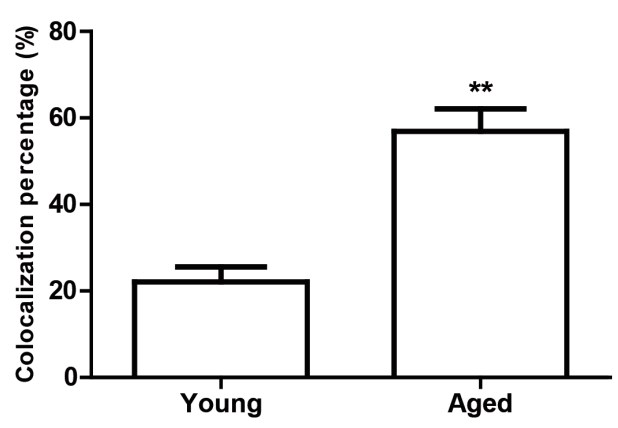

(D) Cortex region of rat kidney
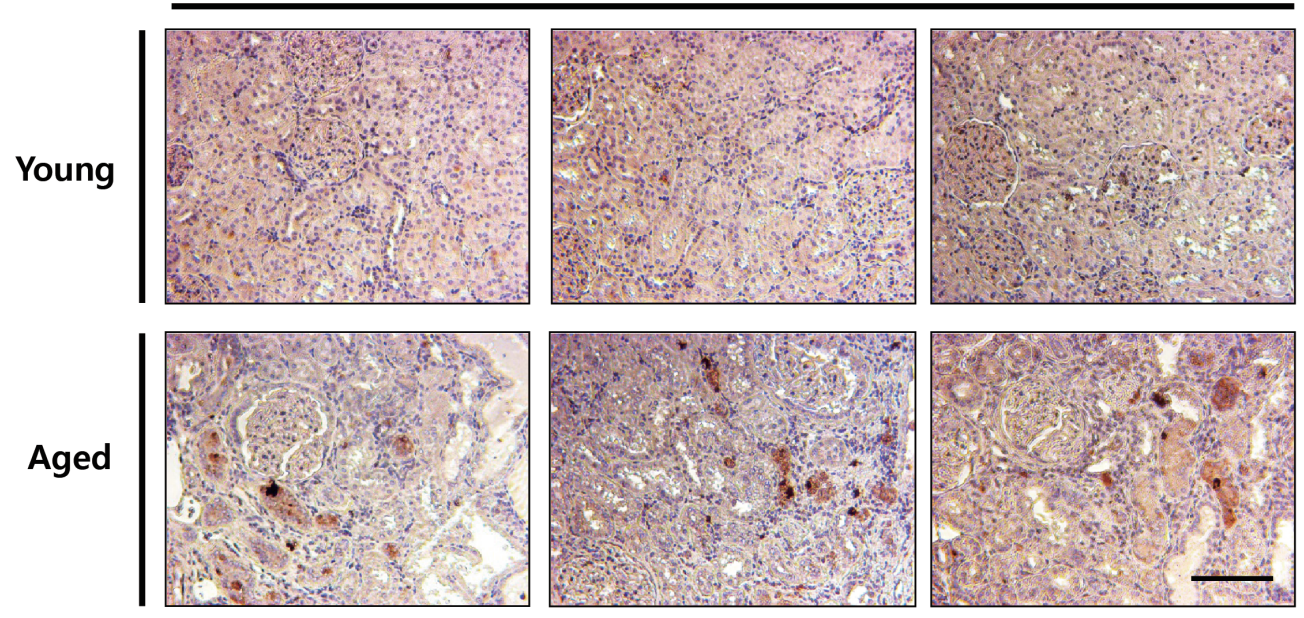

CD68 positive : Macrophage Counter staining : Haematoxylin

Figure 2: Increased NF-кBIZ protein levels were associated with macrophage infiltration in aged rat kidneys. A. NF$\kappa \mathrm{BIZ}$ and macrophage marker protein $\mathrm{CD}-68$ were detected using two primary antibodies. NF- $\mathrm{kBIZ}$ antibody and CD-68 antibody were simultaneously administered to young and old kidney paraffin sections for double immunofluorescence staining. Tissue sections were counterstained with Hoechst33342. After staining, fluorescence was observed by confocal microscopy. Scale bar $=200 \mu \mathrm{m}$. B. CD68 positive area from immunofluorescence staining were quantified. $* * P<0.01$ vs. the young group. C. Colocalization percentage was calculated based on immunofluorescence staining data. $* * P<0.01 v s$. the young group. D. Increased macrophage infiltration in old kidneys was confirmed by immunostaining kidney cortex sections for CD-68 (brown); slides were counterstained with haematoxylin (blue). The upper pictures represent young kidneys and the lower pictures aged kidneys. Scale bar $=100 \mu \mathrm{m}$. 


\section{Modulation of IL-6/MCP-1 by NF-אBIZ in LPS- treated macrophages}

In vitro experiments were conducted to further

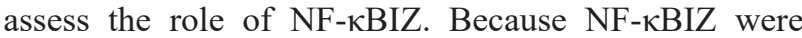
elevated in the macrophages of old rats, peritoneal derived macrophages were utilized to confirm the previously discovered role. LPS $(500 \mathrm{ng} / \mathrm{ml})$ treatment rapidly induced an increase in the protein level of NF-kBIZ peritoneal macrophages (Supplementary Figure 2A), and increased Nfkbiz mRNA expression (Supplementary Figure S2B). Next, we examined the mRNA levels of several cytokines known to be transcribed by NF- $\mathrm{KB}$ activation. LPS treatment induced the up-regulations of $I l l b$ and $T n f a$ mRNA rapidly, and of Mcpl and $I l 6$ rather later (Supplementary Figure 2B). These observations concur with previous reports that NF-KBIZ-related genes are induced in a secondary manner $[8,9]$.

To confirm the role played by NF-kBIZ in the inductions of specific cytokines, a NF-kBIZ knock-down experiment was conducted using siRNA. Nfkbiz siRNA $(2.5 \mathrm{nM})$ significantly reduced the mRNA and protein expressions in peritoneal macrophages (Supplementary

(A)

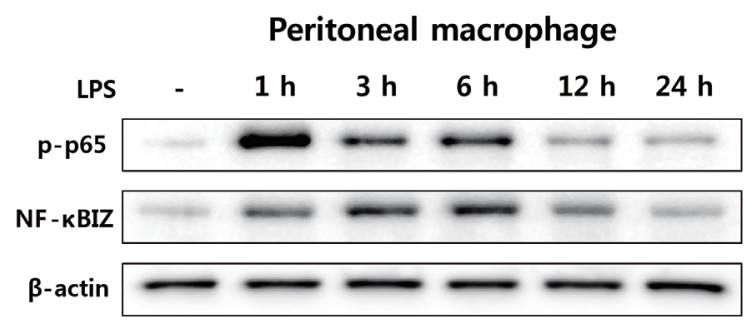

Figure S3A, S3B). In addition, when NF-kBIZ was knocked-down, the mRNA expression levels of $I l 6$ and $M c p 1$ induced by LPS were significantly reduced (Supplementary Figure 3C). However, the mRNAs of $I l 1 b$ and Tnfa were not influenced by NF-kBIZ siRNA, indicating these cytokines are not associated with NF$\kappa B I Z$ (Supplementary Figure 3C). Collectively, these results confirm the previously described role of NF- $\mathrm{KBIZ}$ and demonstrate NF- $\mathrm{KBIZ}$ participates in the inductions of IL-6 and MCP-1.

\section{Effects of oxidative stress on the induction of NF- $\kappa B I Z$ in macrophages by LPS}

As oxidative stress is causally linked with inflammation and aging, and plays an important role as a second signaling messenger $[2,21]$, we examined the role of oxidative stress on NF-kBIZ activation further. Treatment of macrophages with LPS induced p65 activation (p65 phosphorylation) and increase NF$\mathrm{BBIZ}$ protein levels (Figure $3 \mathrm{~A}$ ), which were sustained through $12 \mathrm{~h}$ after LPS treatment (Figure 3A). LPS

(B)

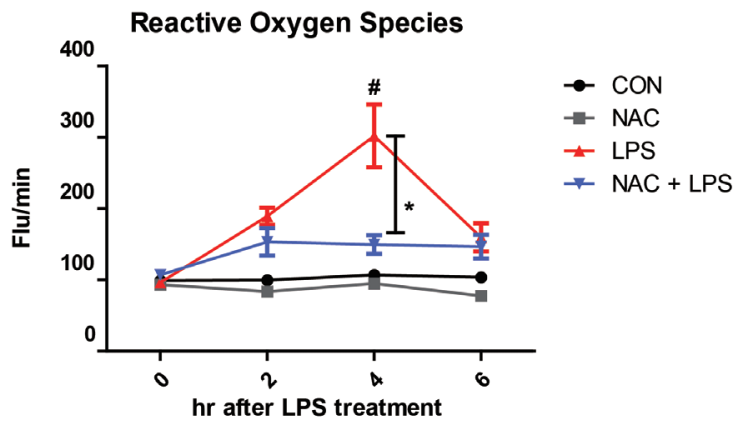

(C)

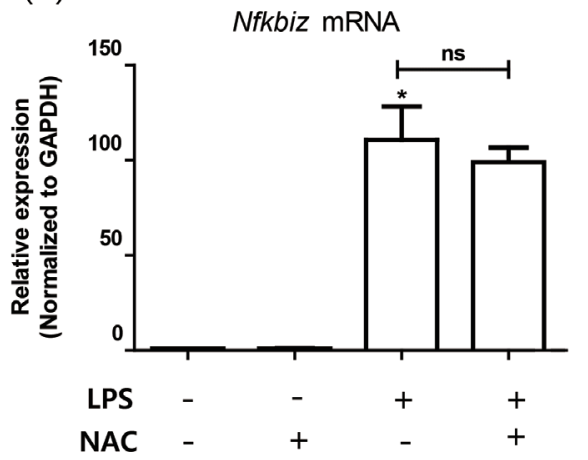

(D)

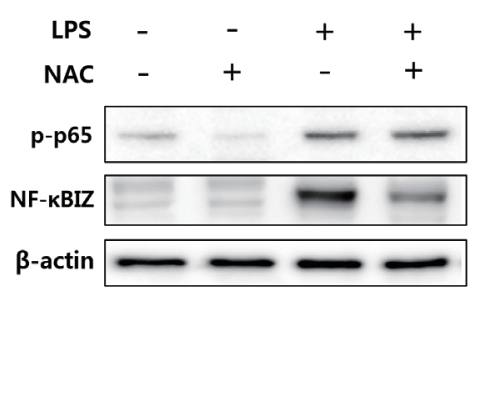

(E)

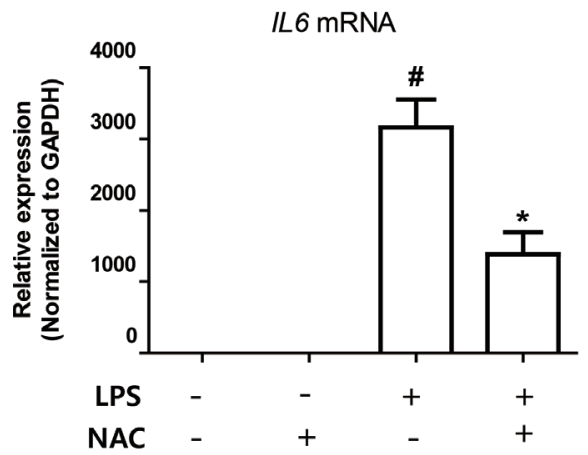

Figure 3: Effect of oxidative stress on NF-кBIZ activation in macrophages. A. Western blotting was performed to examine the time-dependent expression of NF-KBIZ and p65 activation in LPS treated macrophages. $\beta$-Actin was used as the loading control. B. Oxidative stresses were measured using DCFDA in LPS-treated macrophages pretreated or not with NAC. Data are expressed as means \pm SEMs. ${ }^{*} P<0.05$ vs. non-treated macrophages. $\# P<0.05$ vs. LPS treated macrophages. C. $N f k b i z$ mRNA levels were assessed by qPCR in LPS-treated macrophages pretreated with or without NAC. Results were normalized versus Gapdh. ${ }^{*} P<0.05$ vs. non-treated macrophages. D. Western blotting was performed to investigate the effects of NAC on the protein expression of NF-kBIZ and activation of p65 in LPS treated macrophages. $\beta$-Actin was used as the loading control. E. mRNA expressions of Il6 were measured by qPCR in LPS-treated macrophages pretreated with or without NAC. Data are expressed as means \pm SEMs. ${ }^{*} P<0.05$ vs. non-treated macrophages. $\# P<0.05 v s$. LPS treated macrophages. 
also increased oxidative stress as determined by ROS levels, which peaked after $4 \mathrm{~h}$ of LPS treatment (Figure $3 \mathrm{~B})$. To determine whether the scavenging of oxidative stress suppresses NF- $\mathrm{KBIZ}$ expression, we pretreated macrophages with $\mathrm{N}$-acetyl cysteine (NAC; a wellknown ROS scavenger), and found NAC pretreatment significantly reduced LPS-induced oxidative stress (Figure 3B). Interestingly, NAC did not affect the activation of p65 (as determined by p65 phosphorylation) or upregulation of NF- $\kappa$ BIZ mRNA by LPS (Figures 3C, 3D). However, NAC pretreatment decreased NF- $\kappa$ BIZ protein levels in macrophages (Figure 3D), and reduced the IL-6 mRNA expression (Figure $3 \mathrm{E}$ ). These results indicate that oxidative stress is associated with the LPS-induced upregulation of $\mathrm{NF}-\kappa \mathrm{BIZ}$ protein in macrophages.

\section{LPS-induced NF-кBIZ activation during aging}

To investigate the effects of oxidative stress and NF- $\kappa$ BIZ during aging, we checked the effects of aging on inflammation-induced oxidative stress and NF- $\kappa \mathrm{BIZ}$ activation in kidney tissues. Young and old rats were administered LPS ( $2 \mathrm{mg} / \mathrm{kg})$, which has been extensively used in studies on inflammation. Aged rat kidneys showed significantly higher basal levels of oxidative stress (Figure 4A), and higher increases in oxidative stress by LPS treatment (Figure 4A). In addition, NF- $\kappa$ BIZ and IL-6 protein levels were also higher in aged rat kidneys (Figure 4B, 4C) when determined by Western blot and ELISA respectively. These increases were followed by an increase in the downstream signaling of IL-6 (Figure 4D). STAT3 phosphorylation was highly induced only in aged rat against LPS (Figure 4D). These findings suggest the possible role of oxidative stress and NF- $\kappa \mathrm{BIZ}$ in the response differences against LPS in young and aged rat kidney.

\section{The relation between age-associated renal fibrosis and increased NF-кBIZ-related signaling}

To elucidate the physiological impact of NF- $\mathrm{BIZ}$ up-regulation during aging, we examined changes induced
(A)
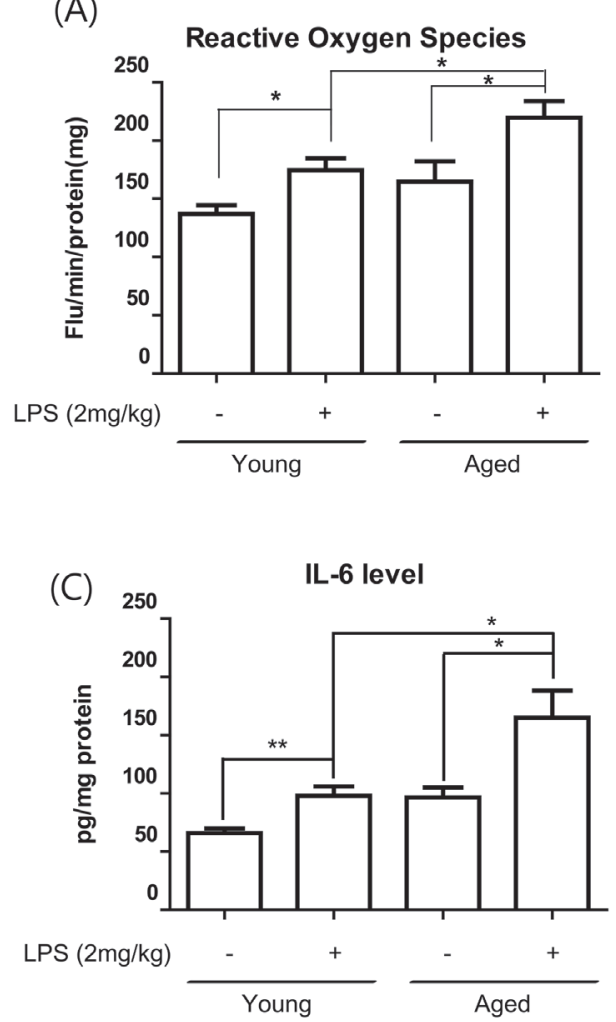

(B)

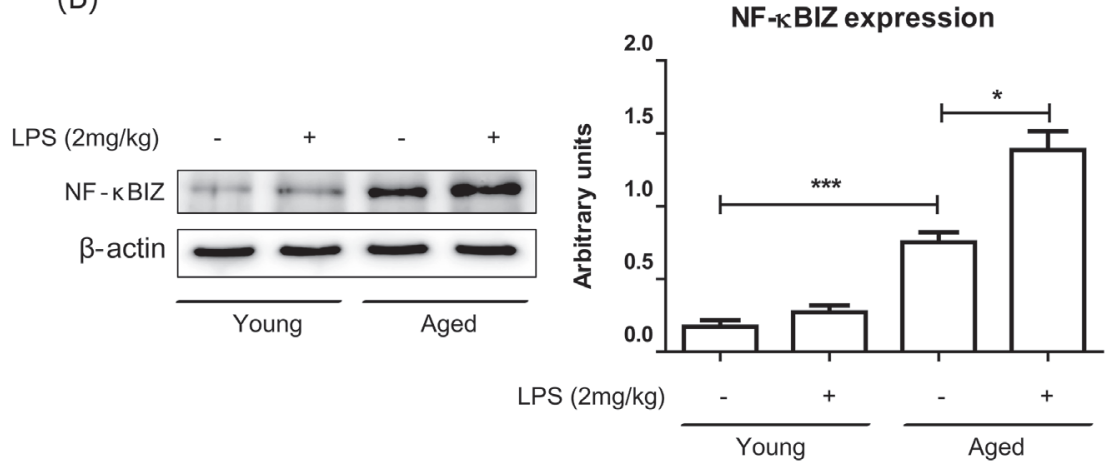

(D)

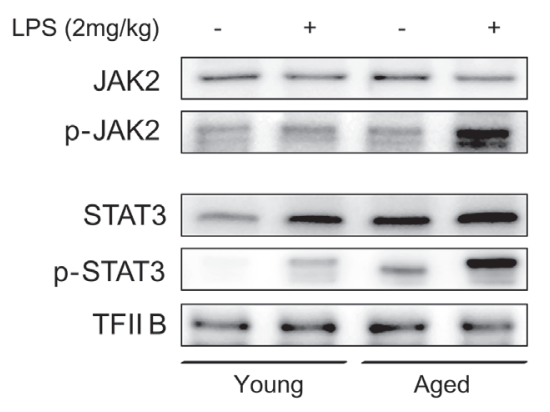

Figure 4: Aging potentiated LPS-induced NF-кBIZ activation. LPS ( $2 \mathrm{mg} / \mathrm{kg}$ ) was administered to young and old rats to determine the effects of aging on LPS-induced oxidative stress increased and NF- $\kappa B I Z$ activation. A. Oxidative stress was measured using DCFDA in young and old rat kidney homogenates pretreated with or without LPS. Data are expressed as means \pm SEMs. $* P<0.05$. B. Western blotting was performed to assess NF- $\kappa$ BIZ protein levels in the kidneys of LPS-treated young and old rats. $\beta$-Actin was used as the loading control. C. IL-6 levels in young and old rat kidney homogenates were determined by ELISA. Data are expressed as means \pm SEMs. $* P<0.05$. $* * P<0.01$. D. IL-6 downstream signaling pathway (JAK-STAT pathway) were detected in the kidneys of young and old rats treated with or without LPS. Western blotting was performed to assess JAK2 and phosphorylated-JAK2 protein levels in cytosolic fractions of aged kidneys, and Stat3 and phosphorylated-Stat3 in nuclear fractions of aged kidneys. TF-IIB was used as the loading control. 
at the molecular and microscopic levels by aging. It has been well established renal aging is associated with structural changes, such as, renal fibrosis, and that IL-6 and MCP1 are associated with many fibrotic diseases. GO (Gene Ontology) analysis of young and old rat kidneys also revealed that responses of wounding and inflammatory response genes were most changed during aging (Supplementary Table 4). Given renal aging is associated with structural changes in kidneys and that NF- $\kappa$ BIZ-related IL- 6 and MCP-1 are fibrotic factors, we investigated the effects of $\mathrm{NF}-\kappa \mathrm{BIZ}$ up-regulation on age-associated progressive renal fibrosis. Initially, we investigated age-related renal fibrosis in young and old rat kidneys, staining kidney cortices and medullae with Sirius-red and Masson's Trichrome (Figure 5A). Positively stained fibrotic regions in cortices and levels of fibrosis in medullae increased with aging (Figure 5A). Sirius-red and Masson's Trichrome staining also showed fibrotic positive areas were greater in old rat kidneys (Figure 5B). Extracellular matrix proteins, which are known to be abnormally elevated in fibrotic tissues, were also detected in the kidneys of old rats. In fact, the expressions of pro-collagen1, collagen 1, and pro-collagen 3 were only detected in aged kidneys (Figure 5C), and fibronectin (FN) levels were elevated (Figure 5C), indicating ageassociated renal fibrosis had occurred, which concurs with previous reports [16]. In addition, a correlation was found between severity of fibrosis (areas stained by Sirius red) and NF- $\kappa$ BIZ expression levels $\left(\mathrm{R}^{2}=0.8038\right.$, Figure 5D).

\section{Suppression of TGF $\beta$-induced kidney fibroblast activation by knock-down of macrophage NF- KBIZ}

To determine the effects of the up-regulations of NF- $\mathrm{kBIZ}$ and related cytokines on fibrosis, we used mouse primary kidney fibroblasts. TGF $\beta$ plays pivotal role in many fibrotic diseases by activating fibroblasts to myofibroblasts, which predominate in fibrotic regions. As shown in Figure 6A, TGF $\beta$ treatment significantly increased its downstream signaling, as evidenced by the
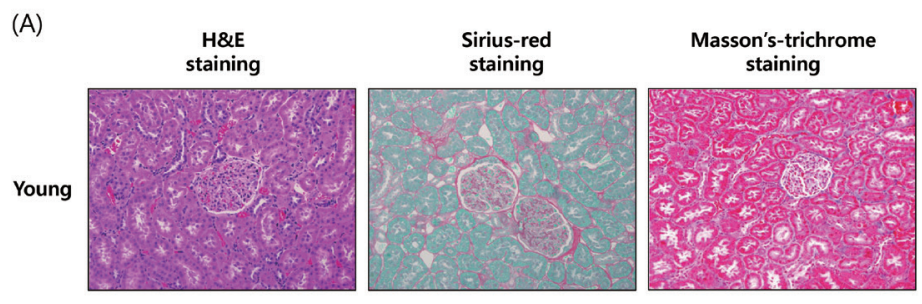

(B)
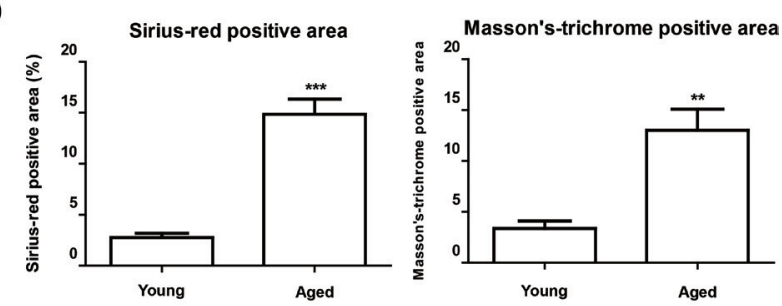

(C)

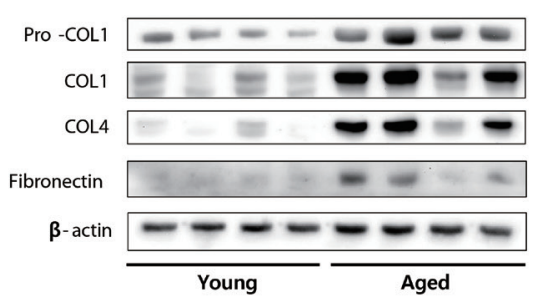

(D)

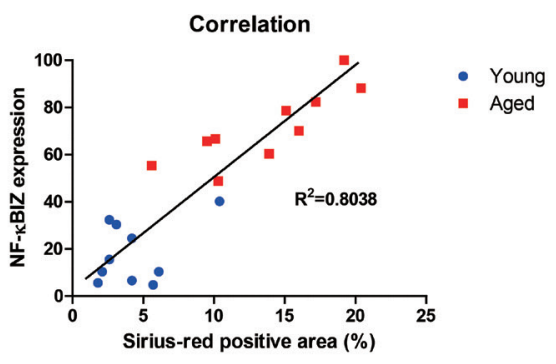

Figure 5: Relation between age-associated renal fibrosis and increased NF-кBIZ related signaling. A. Aging increased fibrosis in kidney cortices and medullae. Young and aged kidney cortices and medullae were histologically stained for fibrosis. H\&E staining, Sirius-red staining, and Masson's trichrome staining showed more renal fibrosis in the cortices of aged rat kidneys. Fibrosis scores were assigned based on Sirius-red staining intensities in kidney cortices $(n=6)$. Scale bar $=100 \mu \mathrm{m}$. B. Fibrotic areas were calculated based on Sirius-red and Masson's Trichrome staining. C. Aging increased the levels of fibrosis-related proteins. Western blotting was performed to assess the nuclear protein levels of pro-collagen1, collagen1, pro-collagen3, and fibronectin. $\beta$-Actin was used as loading control. D.

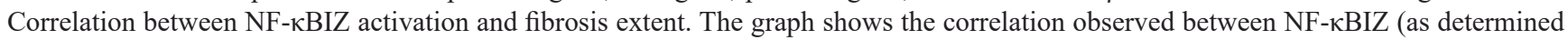
by Western blotting) and fibrosis scores. 
phosphorylation of SMAD, and increased expressions of $\alpha$-SMA and FN (Figure 6A, 6B). To determine whether peritoneal macrophage derived cytokines promote the activation of fibroblasts induced by TGF $\beta$, we used the medium of peritoneal macrophages stimulated with LPS. Although LPS-conditioned medium did not influence fibroblast activation (data not shown), TGF $\beta$ treatment and LPS-conditioned medium significantly increased the downstream signaling of TGF $\beta$ (Figure 6A). In addition, LPS conditioned medium significantly increased TGF $\beta$ induced fibroblast activation based on increases in $\alpha$-SMA and FN levels (Figure 6A, 6B).

Finally, we investigated the effects of NF- $\mathrm{kBIZ}$ and related cytokines on fibroblast activation. LPS conditioned medium from NF- $\kappa B I Z$ deficient macrophages had no effect on the TGF $\beta$-induced activation of fibroblasts (Figure 6C, 6D), indicating NF-kBIZ related cytokines (IL-6 and MCP-1) caused the observed increase in fibroblast activation (Figure 6C, 6D). These findings show the role played by NF-kBIZ and related cytokines in TGF $\beta$-induced fibroblast activation.

\section{DISCUSSION}

Previous studies have demonstrated NF-кBIZ plays critical roles in macrophages, NK cells, and $\mathrm{T}$ cells $[8,9,22,23]$. More recent studies have focused of the physiological and pathological roles of NF-KBIZ in relation to immunity and inflammation $[25,26]$. However, although the roles played by NF- $\mathrm{kBIZ}$ in several immunerelated diseases have been extensively researched, the present study is first to describe the role of NF-KBIZ during aging. We first observed that NF- $\mathrm{kBIZ}$ was up-regulated during aging by using RNA-sequencing analysis to analyze NGS data. Further biochemical analysis confirmed the importance of NF- $\mathrm{KBIZ}$ and its related signaling in aged rat kidneys. Oxidative stresses were found to be associated with increased NF- $\mathrm{KBIZ}$ activation in macrophages and in a LPS-treated aged rat kidney model. Based on our interpretations of bioinformatics data and biochemical results, we describe the role played by NF$\kappa \mathrm{BIZ}$ during age-associated renal fibrosis. Furthermore, we believe this investigation provides potential targets for the treatment of age-associated progressive renal fibrosis.
(A)

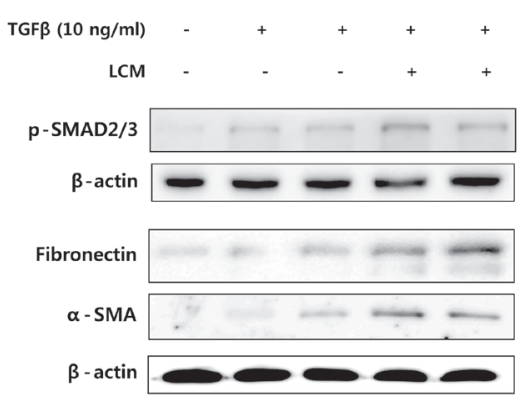

(C)

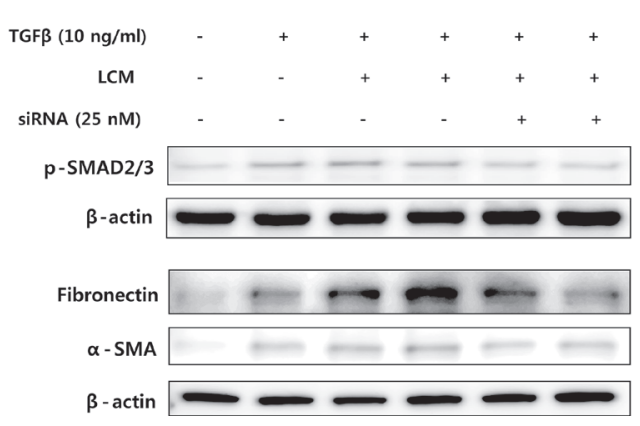

(B)

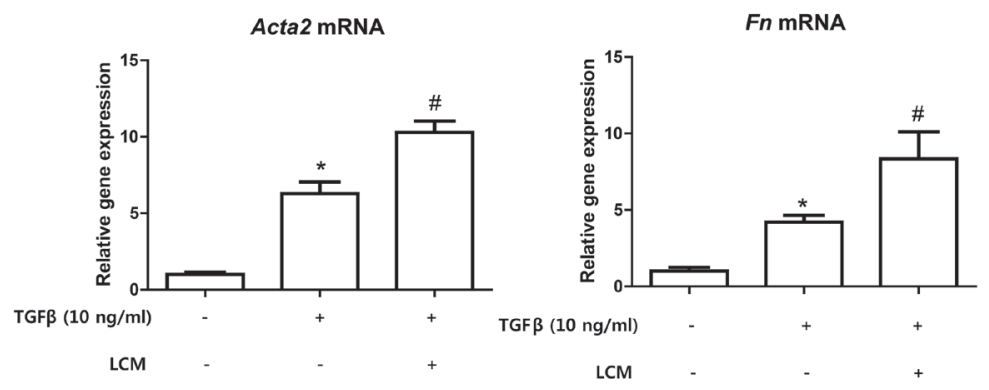

(D)

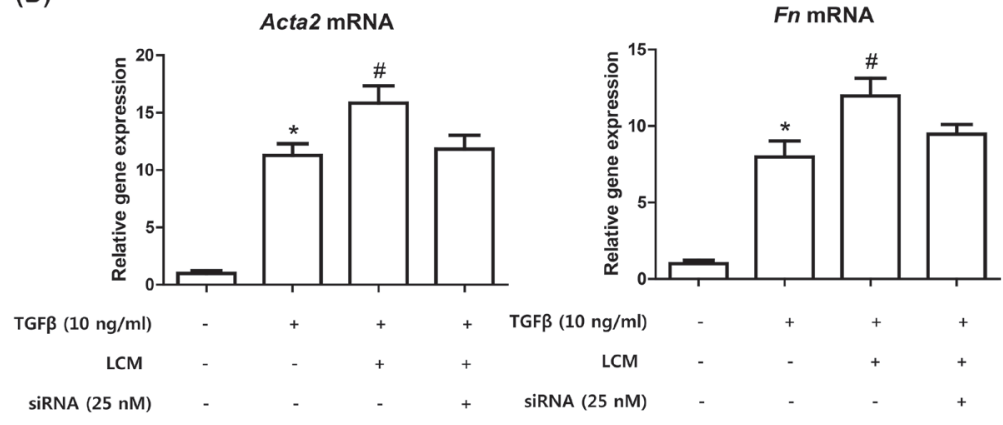

Figure 6: Knock-down of NF-кBIZ in macrophages reduced TGFß-induced kidney fibroblast activation. A. Kidney fibroblasts were treated with $1 \mathrm{ng} / \mathrm{ml}$ of TGF $\beta$ with or without LPS-conditioned macrophage medium. Western blotting was performed to detect SMAD-2/3 phosphorylation and the protein levels of $\alpha$-SMA and FN in kidney fibroblasts. $\beta$-Actin was used as loading control. B. qPCR were performed to detect increases in the mRNA levels of Acta 2 and $F n$ in fibroblasts. qPCR results were normalized versus Gapdh. Data are expressed as means \pm SEMs. $* P<0.05 v s$. non-treated fibroblasts. $\# P<0.05 v s$. TGF $\beta$ treated fibroblasts. LCM, LPS-conditioned medium. C. NF-kBIZ knocked-down kidney fibroblasts were treated with $1 \mathrm{ng} / \mathrm{ml}$ of TGF $\beta$ with or without LPS-conditioned macrophage medium. Western blotting was used to detect phosphorylated SMAD-2 and to assess the protein levels of $\alpha$-SMA and FN. $\beta$-Actin was used as the loading control. D. qPCR was performed to detect the mRNA levels of Acta 2 and $F n$ in fibroblasts. qPCR results were normalized versus Gapdh. Data are expressed as means \pm SEMs. ${ }^{*} P<0.05$ vs. non-treated fibroblasts. $\# P<0.05$ vs. TGF $\beta$ treated fibroblasts. LCM, LPS-conditioned medium. 
The molecular basis of aging-related inflammation highlights the importance of the molecular events underlying chronic inflammation in aging and age-related diseases [21]. Chronic inflammation has been blamed for renal diseases in the elderly [26]. A study on experimental and human renal disease showed the involvement of inflammation in renal fibrosis induced by diverse diseases process, including aging [18]. In the context of renal inflammation, NF- $\mathrm{KB}$ is a key player in the pathogenesis of renal disease whether aging related or not [27]. Previous studies have revealed the importance of NF- $\kappa B$ in the aging process, especially in aged kidneys [20] and brain [28]. Furthermore, because NF- $\kappa \mathrm{B}$ is tightly regulated at multiple levels [29], even by other NF- $\kappa$ B family members, these regulators are also interesting targets in terms of the regulation of $\mathrm{NF}-\kappa \mathrm{B}$ signaling.

$\mathrm{NF}-\kappa \mathrm{BIZ}$ has been recently identified and implicated in the differential expressions of NF- $\mathrm{B}$ targeted genes in immune cells. Upon activation, NF- $\mathrm{BIZ}$ interacts with the p50 unit of NF- $\mathrm{NB}$, and thus, regulates its transcriptional activity [8]. Importantly, in the present study, the NF- $\kappa B I Z$ gene was the only NF-кB family member found to be upregulated by RNA-Seq using NGS data. In addition, NF$\kappa \mathrm{BIZ}$ related cytokines (IL-6 and MCP-1) were also found to be up-regulated in aged rat kidney by RNA-Seq analysis which were further verified by biological experiments. Further analysis revealed that NF- $\mathrm{BBIZ}$ co-localized with infiltrating macrophages in old rats, indicating

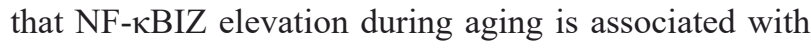
increased macrophage invasion. Interestingly, NF- $\kappa \mathrm{BIZ}$ up-regulation was recently reported in a senescentassociated secretory fibroblast phenotype and blocking NF- $\kappa$ BIZ activation prevented senescence [30]. Since senescent-associated cytokines and macrophages play pivotal roles in the regulation of renal inflammation and aging, these findings hint at the physiological meaning of the up-regulations of NF- $\kappa \mathrm{BIZ}$ at the transcription and protein levels in aged rat kidneys, and place focus on its pathophysiological role in macrophages.

Renal fibrosis is the final common pathway of all kidney diseases leading to chronic kidney disease [11]. Although the outcomes of renal fibrosis have been wellestablished, fibrogenesis and the factors that contribute to the progression of fibrosis have yet to be elucidated [13]. Nevertheless, of the many factors responsible for kidney fibrogenesis, aging has been established to be a crucial reason for renal structural changes [17]. Furthermore, because aging is associated with prolonged inflammation, aging promotes chronic inflammation and the pathogeneses of various kidney diseases, including fibrosis [31].

Cytokines are known to play complex roles in fibrosis [32]. In particular, accumulating evidence suggests that IL-6 and MCP-1 play pivotal roles. Although IL-6 is recognized as a pleiotropic cytokine, several studies have revealed its importance in fibrotic diseases. In particular,
IL-6 was found to enhance TGF- $\beta$ induced SMAD activation in fibrosis $[33,34]$. Increased IL-6 signaling upregulated the trafficking of TGF- $\beta$ receptors to non-lipid raft-associated pools leading to enhanced TGF- $\beta$ signaling [33]. Furthermore, activation of STAT3-dependent pathways by IL-6 trans-signaling enhanced TGF- $\beta$ signaling of fibrosis [35]. Most importantly, IL-6 signaling was observed to drive fibrosis signaling in unresolved inflammation by inducing Th1 cell response [36]. STAT3 is also implicated in several fibrotic kidney diseases [37]. Interestingly, STAT3 was implicated as multi-organ target for tissue fibrosis which is not restricted to kidney fibrosis $[38,39]$. MCP-1 has been implicated to participate in several types of fibrosis, including renal fibrosis [40, 41]. Although the mechanism has not been precisely identified, the profibrotic actions of $\mathrm{MCP}-1$ are believed to reflect its role in mononuclear cell recruitment and activation. The present study also indicates that these cytokines are associated with renal fibrosis. Cytokines derived from macrophages stimulated with LPS were found to enhance TGF- $\beta$ induced fibroblast activation in vitro. Furthermore, knockdown of NF-кBIZ decreased macrophage productions of IL- 6 and MCP-1, and reductions in IL-6 and MCP-1 levels in macrophages achieved by NF- $\kappa$ BIZ knock-down diminished these fibrogenic effects. These findings suggest that NF- $\mathrm{KBIZ}$ dependent cytokines play important roles on fibroblasts activation.

In conclusion, the present study demonstrates a new role for $\mathrm{NF}-\kappa \mathrm{BIZ}$ in age-associated progressive renal fibrosis (summarized in Supplementary Figure 4). NF-кBIZ expression was found to be up-regulated by RNA-Seq analysis, and IL-6 and MCP-1 (both NF$\kappa \mathrm{B}$ target genes regulated by $\mathrm{NF}-\kappa \mathrm{BIZ}$ ) were observed to be significantly up-regulated in aged rat kidneys. Furthermore, the up-regulation of NF- $\kappa \mathrm{BIZ}$ in aged rat kidneys was associated with increased macrophage infiltration. Further experiments showed that oxidative stress was associated with increased expression of NF$\kappa \mathrm{BIZ}$ in LPS-stimulated macrophages and kidney tissues. In addition, increased NF- $\mathrm{KBIZ}$ expression in aged kidneys was found to be related to the severity of renal fibrosis. Experiments in peritoneal macrophages and primary kidney fibroblasts demonstrated the important role of NF- $\kappa \mathrm{BIZ}$ in the acceleration of fibroblast activation induced by TGF- $\beta$ in fibroblasts. Taken together, this study demonstrates NF- $\kappa B I Z$ is up-regulated in aged rat kidneys and suggests the importance of NF- $\kappa \mathrm{BIZ}$ in age-associated progressive renal fibrosis. 


\section{MATERIALS AND METHODS}

\section{Materials}

LPS (Escherichia coli serotype O111:B5) was purchased from Sigma-Aldrich (Sigma-Aldrich, St. Louis, MO, USA). Antibodies were obtained from Santa Cruz Biotechnology (Santa Cruz, CA, USA), Cell Signaling Technology (New England BioLabs, Hertfordshire, UK), or Abcam (Cambridge, MA, USA). Primers for qPCR were synthesized by Bioneer, Inc. (Daejeon, Korea). Polyvinylidene difluoride (PVDF) membranes were obtained from Millipore (Bedford, MA, USA). Sterile plastic ware for tissue culture was purchased from SPL (Seoul, Korea). All other reagents were purchased from Sigma if not otherwise stated.

\section{Animals}

RNA-Seq data obtained by NGS analysis were obtained from previous results [42]. To assess the biological and biochemical effects of aging on renal inflammation and fibrosis, male Sprague Dawley (SD) rats aged 6 months (young) and 24 (old) months (Samtako, Osong, Korea) were used. Rats were maintained under controlled environmental conditions under a $12-\mathrm{h} / 12-\mathrm{h}$ light/dark cycle, and allowed ad libitum access to water and a standard laboratory diet. Serum was collected for biochemical analysis. Kidneys were collected and either frozen immediately in liquid nitrogen for quantitative polymerase chain reaction (qPCR), Western blot, and biochemical tests, or fixed in neutral-buffered formalin for histochemical examination. The animal protocol used in this study was reviewed and approved of by the Pusan National University-Institutional Animal Care and Use Committee (PNU-IACUC) with respect to study ethicality.

To investigate the effects of aging on LPS-induced renal inflammation. Lipopolysaccharide (LPS, $2 \mathrm{mg} / \mathrm{kg}$ body weight) was injected intraperitoneally into young and old male SD rats. Animals were euthanized at $12 \mathrm{~h}$ after injection. Serum and kidneys were collected for biochemical analysis.

\section{Cell culture experiments}

Primary cultured mouse peritoneal macrophages and primary cultured mouse kidney fibroblasts were used to evaluate the relationship between oxidative stress and

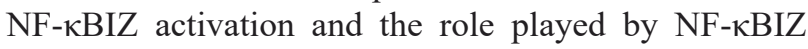
related cytokines in fibroblast activation. Peritoneal macrophages were obtained from mouse peritoneal, as described previously. Briefly, $5 \mathrm{ml}$ of $3 \%$ thioglycollate medium was injected into the peritoneal cavities of C57/
BL6 mice, and 4 days later, peritoneal macrophages were collected with a syringe and needle, seeded in cell culture dishes for further experiments. LPS was treated according to experiment's condition. Primary cultured mouse kidney fibroblasts were obtained from Cell Biologics (Chicago, IL). Cells were cultured on gelatin-based coating solution (Sigma-Aldrich, St. Louis, MO), and activated with $2 \mathrm{ng} /$ $\mathrm{ml}$ of TGF $\beta$ (eBioscience, San Diego, CA). To observe the effects of NF- $\mathrm{\kappa BIZ}$ on fibroblast activation, macrophage medium derived supernatants were transferred to fibroblast medium.

\section{Protein extraction from tissues and cells}

All solutions, tubes, and centrifuges were maintained at $0-4^{\circ} \mathrm{C}$. PRO-PREP protein extraction solution (Intron Biotech Inc., Korea) was used to extract total protein lysates from tissues or cells according to the manufacturer's instructions. To extract nuclear protein, tissues or cells were washed with ice-cold PBS, suspended in $10 \mathrm{mM}$ Tris ( $\mathrm{pH} 8.0$ ) containing $1.5 \mathrm{mM} \mathrm{MgCl}_{2}, 1$ $\mathrm{mM}$ dithiothreitol, $0.1 \% \mathrm{NP}-40$, and protease inhibitors, homogenized, and incubated on ice for $15 \mathrm{~min}$, and centrifuged at $14,000 \mathrm{~g}$ for $15 \mathrm{~min}$ at $4^{\circ} \mathrm{C}$. Supernatants were used as cytosolic fractions and pellets were resuspended in $10 \mathrm{mM}$ Tris (pH 8.0) containing $50 \mathrm{mM} \mathrm{KCl}$, $100 \mathrm{mM} \mathrm{NaCl}$, and protease inhibitors, incubated on ice for $30 \mathrm{~min}$, and centrifuged at $14,000 \mathrm{~g}$ for $30 \mathrm{~min}$ at $4^{\circ} \mathrm{C}$. The resultant supernatants were used as nuclear fractions.

\section{Western blotting}

Western blot assays were performed as described previously with minor modification [19]. Briefly, nuclear or cytosolic proteins $(20 \sim 100 \mu \mathrm{g}$ of protein) were boiled for $5 \mathrm{~min}$ in gel-loading buffer $(0.125 \mathrm{M}$ Tris-HCl, pH 6.8, 4 \% SDS, $10 \%$ 2-mercaptoethanol, and $0.2 \%$ bromophenol blue) at a volume ratio of 1:1. Samples containing the same amounts of proteins were then separated by sodium dodecyl sulfate-polyacrylamide gel electrophoresis in $8 \% \sim 15 \%$ acrylamide gels and transferred using a Bio-Rad western system (Bio-Rad, Hercules, CA, USA) to PVDF membranes, which were immediately placed in blocking buffer (5\% non-fat milk) containing $10 \mathrm{mM}$ Tris ( $\mathrm{pH} 7.5), 100 \mathrm{mM} \mathrm{NaCl}$, and $0.1 \%$ Tween 20 . Membranes were then washed in TBS-Tween buffer for $30 \mathrm{~min}$, incubated with specific primary antibodies (dilution 1:500 to 1:2000, Table 1) at $4{ }^{\circ} \mathrm{C}$ overnight, washed for $3 \times 10$-min in TBS-Tween buffer, and incubated with horseradish peroxidaseconjugated anti-mouse antibody (Santa Cruz, 1:10,000), anti-rabbit antibody (Santa Cruz, 1:10,000), or anti-goat antibody (Santa Cruz, $1: 10,000$ ) at $25^{\circ} \mathrm{C}$ for $1 \mathrm{~h}$. Resulting immunoblots were visualized using Western Bright Peroxide solution (Advansta, CA, USA) and Davinch- 
chemi CAS-400 (Davinch-K, Seoul, Korea), according to the manufacturers' instructions.

\section{Isolation of total RNA and qPCR}

Total RNA was isolated as previously described. Briefly, tissue samples were homogenized in the presence of RNAzol ${ }^{\mathrm{TM}}$ ( $2 \mathrm{ml}$ per $100 \mathrm{mg}$ tissue) with a few strokes in a tissue homogenizer. Aliquots of $0.2 \mathrm{ml}$ chloroform per $2 \mathrm{ml}$ homogenate were added and samples were shaken vigorously for $15 \mathrm{~min}$. Aqueous phases were transferred to fresh tubes, to which an equal volume of isopropanol was added. Samples were then left at $4^{\circ} \mathrm{C}$ for $15 \mathrm{~min}$ and centrifuged at $12,000 \mathrm{~g}$ at $4{ }^{\circ} \mathrm{C}$ for $15 \mathrm{~min}$. Supernatants were removed and RNA pellets were washed once with $75 \%$ ethanol by vortexing and then centrifuged at 7,500 $g$ at $4{ }^{\circ} \mathrm{C}$ for $8 \mathrm{~min}$. Pellets were dried for $10-15 \mathrm{~min}$ and dissolved in DEPC-treated water. RNase-free DNasetreated total RNA $(2.0 \mu \mathrm{g})$ was reverse-transcribed using a cDNA synthesis kit from Gendepot (Barker, TX, USA). DEPC-treated water and $250 \mathrm{ng}$ of random primer were added, incubated at $75^{\circ} \mathrm{C}$ for $5 \mathrm{~min}$, and then on ice for 5 min. Aliquots of $2 \mu \mathrm{l}$ of $0.1 \mathrm{M} \mathrm{DTT}, 4 \mu \mathrm{l}$ of $5 \mathrm{X}$ buffer, 4 $\mu \mathrm{l}$ of $2.5 \mathrm{mM} \mathrm{dNTP}, 100 \mathrm{U}$ of reverse transcriptase, and 16.5 $\mathrm{U}$ of RNase inhibitor were added and the mixture was incubated at $37^{\circ} \mathrm{C}$ for $2 \mathrm{~h}$. The reaction was stopped by boiling at $100^{\circ} \mathrm{C}$ for $2 \mathrm{~min}$, and the cDNA so obtained was stored at $-20^{\circ} \mathrm{C}$ until required. qPCR was performed using Sybr-Green and the CFX Connect System (Bio-Rad Laboratories Inc., Hercules, CA, USA). Primer sequences are provided in Supplementary Table 5.

\section{Histopathological analysis}

Kidneys were fixed in $10 \%$ neutral formalin and paraffin-embedded sections were stained with hematoxylin and eosin (H\&E). Sirius-red staining and Masson's Trichrome staining were performed to determine the degree of aging-associated fibrosis, as described previously [43]. Immunohistochemical staining for kidney macrophages was performed using ED-1 antibody.

\section{Measurement of oxidative stress}

RS generation was measured using 2',7'-dichlorodihydro-fluorescein diacetate (DCFDA; a fluorescent probe). For tissue homogenates, $25 \mu \mathrm{M}$ DCFDA was added in $50 \mathrm{mM}$ of phosphate buffer. Changes in fluorescence intensity were measured every $5 \mathrm{~min}$ for $30 \mathrm{~min}$ on a microplate reader (GENios; Tecan Instruments, Salzburg, Austria) using excitation and emission wavelengths of 485 and $530 \mathrm{~nm}$, respectively. For cell culture experiments, after cells had been treated, they were incubated with $10 \mu \mathrm{M}$ carboxy-H $\mathrm{H}_{2}$ CFDA for $10 \mathrm{~min}$ at $37^{\circ} \mathrm{C}$ and washed twice with PBS. Dye oxidation rates were determined by monitoring changes in fluorescence intensity every $5 \mathrm{~min}$ for $30 \mathrm{~min}$ using a fluorescence plate reader using excitation and emission wavelengths of 485 and $530 \mathrm{~nm}$, respectively.

\section{Immunofluorescence}

Paraffin-embedded young and old kidney sections were deparaffinized, rehydrated and retrieved. After blocking with $5 \%$ BSA in PBS for $30 \mathrm{~min}$, sections were incubated in a mixture of two primary antibodies overnight at $4^{\circ} \mathrm{C}$. After washing with PBS, sections were incubated with the mixture of two secondary antibodies raised in different species [Alexa Fluor-488 Goat Antirabbit $\operatorname{IgG}(\mathrm{H}+\mathrm{L})$ Antibody (Invitrogen) and Rhodamine RedTM-X Goat Anti-Mouse IgG $(\mathrm{H}+\mathrm{L})$ antibody (Jackson ImmunoResearch, West Grove, PA, USA)] in 1\% BSA for $2 \mathrm{~h}$ at room temperature in the dark. Sections were then counterstained with $1 \mu \mathrm{g} / \mathrm{ml}$ Hoechst $5 \mathrm{~min}$, mounted, and stored in dark at $4^{\circ} \mathrm{C}$. Confocal images were obtained using a FV10i FLUOVIEW Confocal Microscope (Olympus, Tokyo).

\section{siRNA transfection}

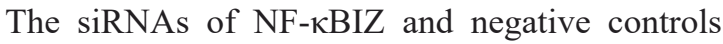
were purchased from Integrated DNA Technologies (IDT, Coralville, IA, USA). Dicer-substrate siRNA methods were used to increase the potency of target gene knock-down. The selected NF-кBIZ siRNAtargeting sequence (duplex1 in experiment) was AUAUUUGUAGUUCUUACUCACGUUGGG. TYE563 fluorescently-labeled transfection control duplex was used for detecting the efficiency of transfection in peritoneal macrophages. Lipofectamine 3000 (Invitrogen) was used to transfect cells with siRNA. For siRNA transfection, cells were seeded in six-well plates, grown for $24 \mathrm{~h}$ to $60-70 \%$ confluence, and then transfected with $25 \mathrm{nM}$ NF- $\mathrm{kBIZ}$ siRNA or negative control siRNA using Lipofectamine 3000 (Invitrogen).

\section{Statistical analysis}

Analysis of variance (ANOVA) was used to analyze intergroup differences. Differences between group means were assessed using Fisher's protected least-significant difference post hoc test. The Student's $t$-test was used to analyze differences between two groups. $P$ values of $<0.05$ were considered statistically significant. Analyses were performed using GrapdPad Prism 5 (GraphPad software, La Jolla, CA). 


\section{ACKNOWLEDGMENTS}

We thank the Korean Aging Tissue Bank for providing research materials.

\section{CONFLICTS OF INTEREST}

The authors declare no competing financial interest.

\section{GRANT SUPPORT}

This work was supported by the National Research Foundation of Korea (NRF) grant funded by the Korea government (MSIP) (No. 2015R1A2A2A01004137).

\section{REFERENCES}

1. Chung HY, Kim HJ, Kim JW, Yu BP. (2001) The inflammation hypothesis of aging: molecular modulation by calorie restriction. Ann N Y Acad Sci. 928, 327-35.

2. Chung HY, Sung B, Jung KJ, Zou Y, Yu BP. (2006) The molecular inflammatory process in aging. Antioxid Redox Signal. 8, 572-81.

3. Montecino-Rodriguez E, Berent-Maoz B, Dorshkind K. (2013) Causes, consequences, and reversal of immune system aging. J Clin Invest. 123, 958-65.

4. Shaw AC, Goldstein DR, Montgomery RR. (2013) Agedependent dysregulation of innate immunity. Nat Rev Immunol. 13,875-87.

5. Kitamura H, Kanehira K, Okita K, Morimatsu M, Saito M. (2000) MAIL, a novel nuclear I kappa B protein that potentiates LPS-induced IL-6 production. FEBS Lett. 485, 53-6.

6. Yamazaki S, Matsuo S, Muta T, Yamamoto M, Akira S, Takeshige K. (2008) Specific requirement of a nuclear protein, IkappaB-zeta, for promoter association of inflammatory transcription regulators. J Biol Chem 283, 32404-11.

7. Yamazaki S, Muta T, Takeshige K. (2001) A novel IkappaB protein, IkappaB-zeta, induced by proinflammatory stimuli, negatively regulates nuclear factor-kappaB in the nuclei. J Biol Chem. 276, 27657-62.

8. Yamamoto M, Yamazaki S, Uematsu S, Sato S, Hemmi H, Hoshino K, Kaisho T, Kuwata H et al., (2004) Regulation of Toll/IL-1-receptor-mediated gene expression by the inducible nuclear protein IkappaBzeta. Nature. 430, 218-22.

9. Hildebrand DG, Alexander E, Hörber S, Lehle S, Obermayer K, Münck NA, Rothfuss O, Frick JS et al.,(2013) I $\kappa \mathrm{B} \zeta$ is a transcriptional key regulator of CCL2/ MCP-1. J Immunol. 190, 4812-20.

10. Samuel CS, Zhao C, Bond CP, Hewitson TD, Amento EP, Summers RJ. (2004) Relaxin-1-deficient mice develop an age-related progression of renal fibrosis. Kidney Int. 65, 2054-64.
11. Liu Y. (2006) Renal fibrosis: new insights into the pathogenesis and therapeutics. Kidney Int. 69, 213-7.

12. Duffield JS. (2014) Cellular and molecular mechanisms in renal fibrosis. J Clin Invest. 124, 2299-306.

13. Hewitson TD. (2012) Fibrosis in the kidney: is a problem shared a problem halved? Fibrogenesis Tissue Repair. 6, 5(Suppl 1):S14. eCollection

14. Floege J, Hackmann B, Kliem V, Kriz W, Alpers CE, Johnson RJ, Kühn KW, Koch KM, Brunkhorst R. (1997) Age-related glomerulosclerosis and interstitial fibrosis in Milan normotensive rats: a podocyte disease. Kidney Int. $51,230-43$.

15. Sangaralingham SJ, Heublein DM, Grande JP, Cataliotti A, Rule AD, McKie PM, Martin FL, Burnett JC Jr. (2011) Urinary C-type natriuretic peptide excretion: a potential novel biomarker for renal fibrosis during aging. Am J Physiol Renal Physiol. 301, F943-52.

16. Cruz CI, Ruiz-Torres P, del Moral RG, Rodríguez-Puyol M, Rodríguez-Puyol D. (2000) Age-related progressive renal fibrosis in rats and its prevention with ACE inhibitors and taurine. Am J Physiol Renal Physiol. 278, F122-9.

17. Rule AD, Amer H, Cornell LD, Taler SJ, Cosio FG, Kremers WK, Textor SC, Stegall MD. (2010) The association between age and nephrosclerosis on renal biopsy among healthy adults. Ann Intern Med. 152, 561-7.

18. Lee SB, Kalluri R. (2010) Mechanistic connection between inflammation and fibrosis. Kidney Int Suppl. 119, S22-6.

19. Gershoni JM, Palade GE. (1983) Protein blotting: principles and applications. Anal Biochem. 131, 1-15.

20. Kim HJ, Kim KW, Yu BP, Chung HY. (2000) The effect of age on cyclooxygenase-2 gene expression: NF-kappaB activation and IkappaBalpha degradation. Free Radic Biol Med. 28, 683-92.

21. Chung HY, Cesari M, Anton S, Marzetti E, Giovannini S, Seo AY, Carter C, Yu BP, Leeuwenburgh C. (2009) Molecular inflammation: underpinnings of aging and agerelated diseases. Ageing Res Rev. 8, 18-30.

22. Miyake T, Satoh T, Kato H, Matsushita K, Kumagai Y, Vandenbon A, Tani T, Muta T, Akira S, Takeuchi O. (2010) $\mathrm{I} \kappa \mathrm{B} \zeta$ is essential for natural killer cell activation in response to IL-12 and IL-18. Proc Natl Acad Sci U S A. 107, 176805 .

23. Okamoto K, Iwai Y, Oh-Hora M, Yamamoto M, Morio T, Aoki K, Ohya K, Jetten AM et al., (2010) IkappaBzeta regulates $\mathrm{T}(\mathrm{H}) 17$ development by cooperating with ROR nuclear receptors. Nature. 464, 1381-5.

24. Nogai H, Wenzel SS, Hailfinger S, Grau M, Kaergel E, Seitz V, Wollert-Wulf B, Pfeifer M et al., (2013) IкB- $\zeta$ controls the constitutive NF- $\kappa \mathrm{B}$ target gene network and survival of ABC DLBCL. Blood. 122, 2242-50.

25. Okuma A, Hoshino K, Ohba T, Fukushi S, Aiba S, Akira S, Ono M, Kaisho T, Muta T. (2013) Enhanced apoptosis by disruption of the STAT3-IкB- $\zeta$ signaling pathway in epithelial cells induces Sjögren's syndrome-like 
autoimmune disease. Immunity. 38, 450-60.

26. Vlassara H, Torreggiani M, Post JB, Zheng F, Uribarri J, Striker GE. (2009) Role of oxidants/inflammation in declining renal function in chronic kidney disease and normal aging. Kidney Int Suppl. 114, S3-11.

27. Sanz AB, Sanchez-Niño MD, Ramos AM, Moreno JA, Santamaria B, Ruiz-Ortega M, Egido J, Ortiz A. (2010) NF-kappaB in renal inflammation. J Am Soc Nephrol. 21, 1254-62.

28. Zhang G, Li J, Purkayastha S, Tang Y, Zhang H, Yin Y, Li B, Liu G, Cai D. (2013) Hypothalamic programming of systemic ageing involving IKK-b, NF-kB and GnRH. Nature 497, 211-6.

29. Oeckinghaus A, Ghosh S. (2009) The NF-kappaB family of transcription factors and its regulation. Cold Spring Harb Perspect Biol. 1, a000034.

30. Lim H, Park H, Kim HP. (2015) Effects of flavonoids on senescence-associated secretory phenotype formation from bleomycin-induced senescence in BJ fibroblasts. Biochem. Pharmacol. 96, 337-348.

31. Zhou XJ, Rakheja D, Yu X, Saxena R, Vaziri ND, Silva FG. (2008) The aging kidney. Kidney Int. 74, 710-20.

32. Borthwick LA, Wynn TA, Fisher AJ. (2013) Cytokine mediated tissue fibrosis. Biochim Biophys Acta. 1832, 1049-60.

33. Zhang XL, Topley N, Ito T, Phillips A. (2005) Interleukin-6 regulation of transforming growth factor (TGF)-beta receptor compartmentalization and turnover enhances TGFbeta1 signaling. J Biol Chem. 280, 12239-45.

34. Lan HY. (2011) Diverse roles of TGF- $\beta /$ Smads in renal fibrosis and inflammation. Int J Biol Sci. 7, 1056-67.

35. O'Reilly S, Ciechomska M, Cant R, van Laar JM. (2014) Interleukin-6 (IL-6) trans signaling drives a STAT3dependent pathway that leads to hyperactive transforming growth factor- $\beta$ (TGF- $\beta$ ) signaling promoting SMAD3 activation and fibrosis via Gremlin protein. J Biol Chem. 289, 9952-60.

36. Fielding CA, Jones GW, McLoughlin RM, McLeod L, Hammond VJ, Uceda J, Williams AS, Lambie M, et al., (2014) Interleukin-6 signaling drives fibrosis in unresolved inflammation. Immunity. 40, 40-50.
37. Pang M, Ma L, Gong R, Tolbert E, Mao H, Ponnusamy M, Chin YE, Yan H, Dworkin LD, Zhuang S. (2010) A novel STAT3 inhibitor, S3I-201, attenuates renal interstitial fibroblast activation and interstitial fibrosis in obstructive nephropathy. Kidney Int. 78, 257-68.

38. Pedroza M, Le TT, Lewis K, Karmouty-Quintana H, To S, George AT, Blackburn MR, Tweardy DJ, Agarwal SK. (2016) STAT-3 contributes to pulmonary fibrosis through epithelial injury and fibroblast-myofibroblast differentiation. FASEB J. 30, 129-40.

39. Xu MY, Hu JJ, Shen J, Wang ML, Zhang QQ, Qu Y, Lu LG. (2014) Stat3 signaling activation crosslinking of TGF- $\beta 1$ in hepatic stellate cell exacerbates liver injury and fibrosis. Biochim Biophys Acta. 1842, 2237-45.

40. Lloyd CM, Minto AW, Dorf ME, Proudfoot A, Wells TN, Salant DJ, Gutierrez-Ramos JC. (1997) RANTES and monocyte chemoattractant protein-1 (MCP-1) play an important role in the inflammatory phase of crescentic nephritis, but only MCP-1 is involved in crescent formation and interstitial fibrosis. J Exp Med. 185, 1371-80.

41. Kitagawa K, Wada T, Furuichi K, Hashimoto H, Ishiwata Y, Asano M, Takeya M, Kuziel WA et al., (2004) Blockade of CCR2 ameliorates progressive fibrosis in kidney. Am J Pathol. 165, 237-46.

42. Park D, Kim BC, Kim CH, Choi YJ, Jeong HO, Kim ME, Lee JS, Park MH, Chung KW, Kim DH, Lee J, Im DS, Yoon S, et al. RNA-seq analysis reveals new evidence for inflammation-related changes in aged kidney. Oncotarget. 2016; 7:30037-48. doi: 10.18632/oncotarget.9152.

43. Huang Y, de Boer WB, Adams LA, MacQuillan G, Rossi E, Rigby P, Raftopoulos SC, Bulsara M, Jeffrey GP. (2013) Image analysis of liver collagen using sirius red is more accurate and correlates better with serum fibrosis markers than trichrome. Liver Int. 33, 1249-56. 